\title{
Challenges and opportunities for health policy and systems research funding in the Western Pacific region
}

\author{
Swee Kheng Khora,b \\ a United Nations University International Institute for Global Health, Kuala Lumpur, Malaysia \\ b Corresponding author: sk.khor@unu.edu
}

\section{Article history}

Publication date: 10 November 2021

Citation: Khor SK. Challenges and opportunities for health policy and systems research funding in the Western Pacific region. Public Health Res Pract. 2021;31(4):e3142123. https://doi. org/10.17061/phrp3142123

\section{Key points}

- Data relating to health policy and systems research (HPSR) funding in the Western Pacific region is not easily accessible. This is mostly for structural reasons such as lack of transparency and absence of disaggregated information about research funding

- HPSR funding is minimal across the region, with health research funding prioritising biomedical/clinical and public health research

- Countries in the Western Pacific need to increase HPSR demand, funding, capability and quality, and translate HPSR output into real-world policies

\section{Abstract}

Objectives and importance of study: This study examines how health policy and systems research (HPSR) is funded in eight countries and areas in the World Health Organization Western Pacific Region (WPRO). The aim of the research is to provide a guide for HPSR practitioners and organisations to understand the landscape of research funding priorities across the WPRO and to inform demand generation and advocacy activities for HPSR funding and output.

Study type: Mixed methods.

Methods: A desk review was conducted relating to HPSR funding, followed by in-depth interviews. Eight countries and areas were selected to represent characteristics of different health systems. Literature reviews included an analysis of available data relating to HPSR funding and national research and development (R\&D) budgets, between 2010 and 2019 (inclusive). In-depth interviews were conducted with 23 stakeholders using an approved interview guide, to assess the attitudes of HPSR funding decision makers towards HPSR, determinants for HPSR and health research funding decisions, and proposals to strengthen HPSR funding and output.

Results: There are four main characteristics of HPSR funding in the WPRO: 1) a general absence of studies on HPSR funding and its determinants; 2) no universally accepted understanding of HPSR; 3) an absence of granular health research funding data in general and for HPSR in particular; and 4) HPSR funding is generally perceived to be minimal. In-depth interviews show that HPSR has different interpretations and emphases across WPRO countries, leading to a fragmented landscape where decision makers generally favour biomedical or clinical research. Participants indicate that political involvement increases overall research funding, especially if there is a clear connection between funders, producers and HPSR users. Suggestions from participants to strengthen HPSR include: appropriately using central agencies to generate demand and raise HPSR as a national priority; adopting interdisciplinary HPSR; and building HPSR capacity and organisational structures. 
Conclusions: HPSR in the Western Pacific region is generally not well funded, with biomedical and public health research often perceived as a higher priority. Although funding is a crucial component of the quality, quantity and relevance of HPSR outputs, HPSR practitioners and organisations must also generate demand for HPSR, build capacity for increasing the quantity and quality of HPSR outputs, and build pathways to translate HPSR outputs into real-world policies.

\section{Introduction}

According to the Alliance for Health Policy and Systems Research, health policy and systems research (HPSR) is an emerging research area that "seeks to understand and improve how societies organise themselves in achieving collective health goals, and how different actors interact in the policy and implementation processes to contribute to policy outcomes". ${ }^{1}$ There are many determinants for successful and impactful HPSR, such as political support, structural determinants of research capacity, organisation of national health systems and how resource allocations are decided, and a society's commitment to research and knowledge generation.

The objectives of this paper are to understand the landscape of and determinants for HPSR funding in selected Western Pacific countries, to enable HPSR practitioners and organisations to develop more effective demand generation and advocacy activities for HPSR funding and output.

\section{Methods}

The eight WPRO countries and areas selected were: Australia, China, Hong Kong Special Administrative Region of the People's Republic of China (Hong Kong), Japan, Malaysia, the Philippines, Singapore and Republic of Korea (South Korea). These countries were chosen to represent different population sizes, income levels, health service sophistication, HPSR capability and accessibility to information and key informant interviews. Our research was divided into two parts: a desk review and in-depth interviews.

\section{Desk review}

A desk review was conducted using the following databases and sources: PubMed, Google Scholar, grey literature, World Bank data, published government reports, national accounts. The search period was 1 January 2010 to 31 December 2019 (10 calendar years). The literature was examined for HPSR funding amounts, any previous studies of determinants of HPSR funding, and qualitative aspects of HPSR output in the eight WPRO countries/territories studied.

\section{In-depth interviews}

In-depth interviews were conducted with senior health or research leaders in selected countries/territories. Participants included (but were not limited to): senior officials working in research organisations or councils, health ministries or agencies; political leaders including in health commissions, funders, finance ministries or agencies; and leading researchers in government, universities and think-tanks.

Separate one-on-one semi-structured interviews were conducted with 23 participants, using the Zoom videoconferencing application, between September and November 2020. The participants were identified through convenience sampling from existing contact networks, through snowballing and referrals, and through desk review. The interviews ranged from 30-75 minutes.

Of the 23 participants, 12 were university academics/ researchers, five were researchers in the health ministry research institutes, three were research funders, one worked in the health policy unit of a department of health, one worked in a healthcare policy think-tank, and one was an independent public health specialist. Ten participants were from middle-income countries (China, Malaysia, the Philippines), and 13 participants from high-income countries/territories (Australia, Hong Kong, Japan, Singapore, South Korea). No invited participant declined to participate. Interview notes were analysed according to the themes: decision-makers for HPSR funding; determinants for HPSR and health research funding decisions; and proposals to strengthen HPSR funding and output.

This study did not obtain ethics approval because the desk review only analysed publicly available information and the in-depth interviews did not discuss confidential or patient-level information. Verbal consent was obtained from all participants as per local ethical requirements.

\section{Results}

Part 1 discusses findings from the desk review. Part 2 describes the findings from the in-depth interviews, and is divided into three sections: decision makers for HPSR funding, determinants for HPSR funding decisions; and proposals to strengthen HPSR funding and output. 


\section{Part 1. HPSR funding: evidence from the desk review}

There was a general absence of published literature about HPSR funding amounts or determinants of funding decisions in the eight selected WPRO countries/territories for the period 2010-2019. There was one publication about HPSR funding in low- and middle-income countries (including some WPRO countries) from 2003. At that time, international sources accounted for $69 \%$ of all HPSR funding, with HPSR producers being "small public institutions or units with an average of three projects, eight researchers and project portfolios worth $\$ 155,000 "$.

Current government financial accounts and World Bank data provide some information about overall research and development (R\&D) funding levels (including health, other sciences, arts, and other areas), health R\&D funding levels, and biomedical or clinical R\&D funding levels. However, HPSR funding levels are not described in available literature.

World Bank data in Figure 1 show that high-income countries (such as Japan, Singapore and South Korea) spend more on R\&D as a percentage of gross domestic product (GDP) than middle-income countries like China, Malaysia and the Philippines. While Figure 1 shows the latest available comparative data for all countries for 2011 and 2013, more recent data show similar trends of higher R\&D spending correlated with higher GDP, with the percentage of total GDP countries/areas spent on R\&D being: Australia 1.87\% (2017); China 2.14\% (2018); Hong Kong 0.86\% (2018); Japan 3.28\% (2018); South Korea
4.53\% (2018); Malaysia 1.04\% (2018), Philippines 0.16\% (2015) and Singapore 1.92\% (2017). ${ }^{3}$

Data from the United Nations Educational, Scientific and Cultural Organization (UNESCO) in Table 2 show incomplete information about medical and health sciences R\&D spending as a percentage of total R\&D spending in the eight countries, but with a range of 4.6-19.5\%. ${ }^{4}$

No publicly available data source shows HPSR funding allocations (either in absolute value or percentages), or determinants of funding decisions for total R\&D, R\&D by categories, or R\&D by subcategories. Therefore, because high-income countries (HICs) appear to spend more on R\&D compared with middle-income countries (MICs), it is possible HPSR funding is also higher in HICs compared with MICs, in both absolute and percentage terms.

The desk review was refined after analysis of findings from the in-depth interviews, which highlighted the following:

\section{There is no universally accepted understanding of HPSR}

The Alliance for Health Policy and Systems Research, based in the World Health Organization headquarters in Geneva, provides a definition of $\mathrm{HPSR}^{1}$ and there is broad understanding of what constitutes research in health policies, health systems and health services. However, based on the in-depth interviews with participants, there does not appear to be a universally accepted understanding of HPSR in the WPRO region.

Figure 1. Total R\&D spending as percentage of GDP in selected Western Pacific countries, 2011 and 2013

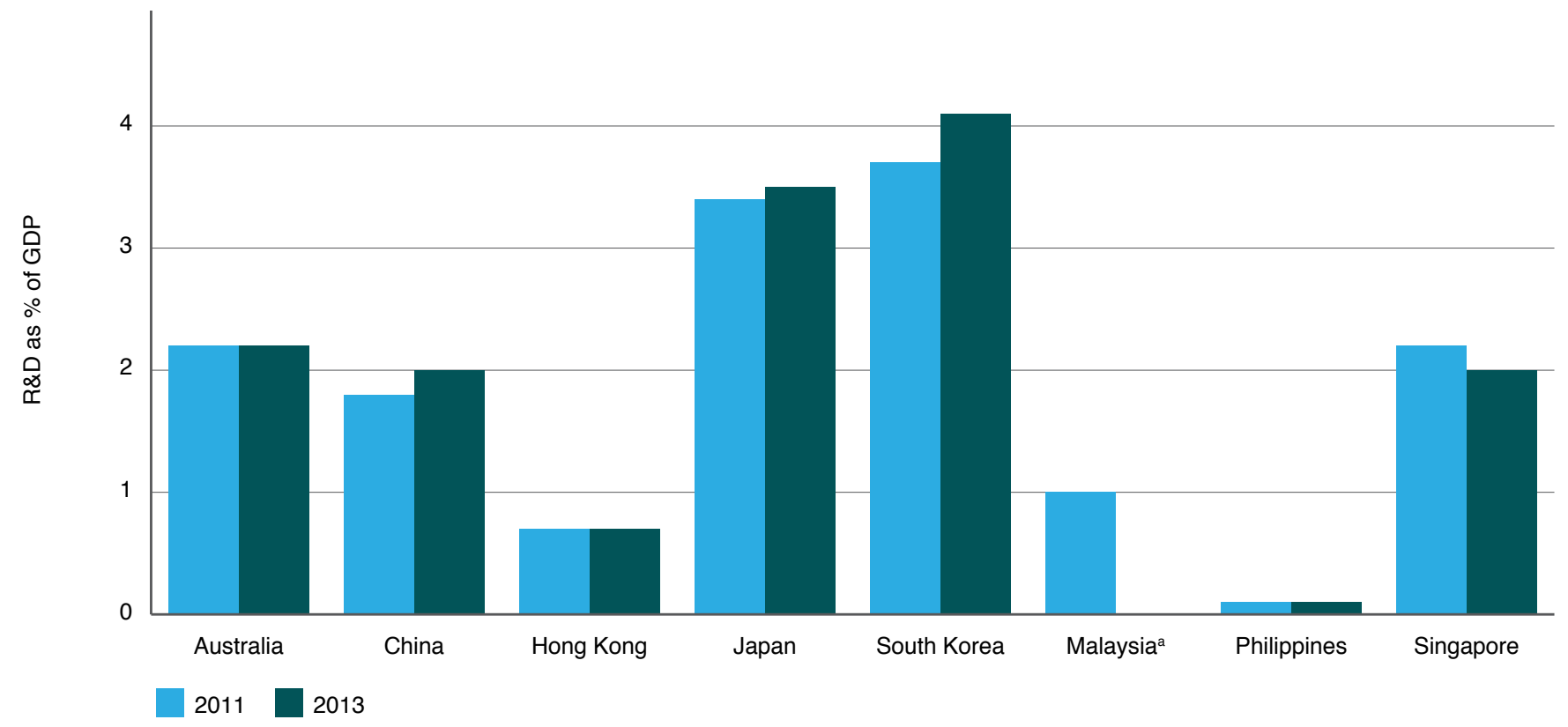

Source: Latest comparative data available from The World Bank. Research and development expenditure (\% of GPD) ${ }^{3}$

a 2013 data for Malaysia was absent 
Table 1. Medical and health sciences R\&D spending as \% of total R\&D spending in eight Western Pacific region countries

\begin{tabular}{lcccccc}
\hline & \multicolumn{5}{c}{ Medical and health sciences R\&D spending as \% of total R\&D spending per year } \\
\cline { 2 - 7 } & 2013 & 2014 & 2015 & 2016 & 2017 & 2018 \\
\hline Australia & NA & NA & NA & NA & NA & NA \\
China & NA & NA & NA & NA & NA & NA \\
Hong Kong & 16.9 & 16.7 & 17.5 & 17.0 & 17.8 & NA \\
Japan & NA & NA & NA & NA & NA & NA \\
South Korea & 11.8 & 11.8 & 4.9 & 4.9 & 4.7 & 4.6 \\
Malaysia & NA & 5.9 & 8.0 & 8.2 & NA & 8.9 \\
Philippines & 4.6 & NA & 9.3 & NA & NA & NA \\
Singapore & 18.5 & 19.0 & 19.1 & 19.5 & 19.0 & NA \\
\hline
\end{tabular}

R\&D = research and development; NA = not available

Source: UNESCO Institute for Statistics. Sustainable development goals: Science, technology and innovation ${ }^{4}$

Because of this, our desk review methodology was broadened, based on suggestions from participants, to include additional discrete terms/areas such as research in 'health policies', 'health systems', 'healthcare services', 'healthcare management', 'healthcare administration' and 'healthcare leadership and governance'.

Despite this, the review showed a relative absence of published data about funding amounts or determinants of funding decisions for these additional search terms, in the eight selected countries/territories.

\section{There is a general absence of granular health} research funding data as a whole (including HPSR), or data on the determinants of its funding

Granular health research funding data are generally absent for the eight countries/territories. Most do publish high-level funding data e.g., total research allocations in national budgets. However, granular data for type of health research (i.e. the breakdown for biomedical, clinical, public health and HPSR) are not publicly available. For example, Japan's Headquarters for Healthcare Policy publishes an annual budget for healthcare R\&D, but there is no disaggregation. ${ }^{5}$

In-depth interviews confirmed that data are not systematically available for HPSR funding or its determinants. Participants suggested several reasons for this: 1) HPSR funding is not yet mature enough or does not exist as a 'standalone' budget category; 2) a large majority of total health research funding goes to 'flagship' biomedical or clinical research categories (as described by two participants), with little detail available for other smaller categories of research; 3) HPSR could be a small component of clinical or public health research projects but it is difficult to isolate the true funding proportions for each research component.

Several participants indicated that government budget and public accounting may not have separate standalone categories for HPSR. This causes two complications: 1) 'pure HPSR' research may be placed in the public health or health services research budget category; 2) HPSR may form components of biomedical, clinical or public health research, which are then categorised in their respective budget categories. Both situations make it difficult to locate and then isolate HPSR-specific data.

There were also no studies found about determinants of HPSR funding, or qualitative aspects of HPSR output such as research volume, citations or impact on real-world policy making. Any such research into the quantity or quality of HPSR output may also encounter methodological challenges because a significant amount of HPSR research is conducted 'in-house' by healthcare delivery organisations (like health ministries) and are not published.

\section{Part 2. Opportunities for HPSR funding: evidence from in-depth interviews}

In-depth interviews were conducted to assess additional information and context for the amount of HPSR funding, determinants of funding decisions, and proposals to strengthen HPSR funding and output. A synthesis of the in-depth interviews provided the following key themes, each divided into three sub-themes.

\section{HPSR funding decision makers}

\section{With different interpretations and emphases for HPSR across WPRO countries, there is a fragmented landscape of decision makers and funders}

All interview participants provided different combinations of decision-making criteria for HPSR funding (in particular) and health or total research funding (in general). A synthesis of all responses indicate three broad categories of HPSR decision-makers: central 
agencies (e.g., ministries of finance, treasuries or cabinets); health agencies (e.g., policy or research units in ministries or departments of health); and a smaller category of philanthropic orgnaisations, think-tanks and privately funded foundations.

A synthesis of interview responses indicated that HPSR producers are mainly in three broad categories: 1) universities or research institutes; 2) health agencies; and 3) foundations or think-tanks. HPSR is mainly used in health agencies or central agencies when planning overall national strategies, and in healthcare delivery agencies like health insurance organisations, hospital groups or non-profit organisations.

All participants also provided different interpretations of the scope, understanding and emphases of HPSR. For example, healthcare services research appears to be more prominent in Singapore and South Korea; health systems research is more prominent in the Philippines and Malaysia, and health policy research is generally present everywhere. One participant stated that health services research became prominent in Singapore after an influential public university launched a research program in that field.

There could be several reasons for these different emphases between countries; 1) different health systems are organised in ways that require different types of research to support their service delivery; 2) healthcare delivery organisations (e.g., Malaysia's Health Ministry), healthcare financing organisations (e.g., social health insurers like the Philippines National Health Insurance Corporation), universities, think-tanks and specialised research institutes (like the Sax Institute in Australia or Institute for Health Policy and System Research in Hong Kong) have different agendas and objectives, meaning that different research areas are emphasised; 3) different historical origins of health research in a country will lead to different HPSR emphases today. For example, HPSR could have been established spontaneously, or carved out from public health, economics or management disciplines, or health policy-making functions, leading to different emphases, decision makers or funding amounts.

Different interpretations of HPSR also lead to difficult comparative budgetary analyses of HPSR funding because public finance categories will differ from country to country. This is complicated by the broad nature of health policies that often intersect with social, environmental and welfare research, with research funds being difficult to disentangle from one agency or sector to another. This fragmented interpretation and emphases for HPSR leads to different decision makers for funding allocations, without a clear theme emerging from the eight countries/territories.

\section{Decision makers favour biomedical or clinical research over HPSR}

All participants perceived that HPSR was underprioritised compared with biomedical and clinical research, in terms of both allocation amounts and success rates in competitive research grants. Across the eight countries/ territories, biomedical and clinical research were highly prized, often an explicit part of national research agendas, and considered to have well-developed research and support infrastructure compared with HPSR. One clear example was Singapore's focus on 'science commercialisation' as a health research strategy. ${ }^{6}$

Participants suggested several reasons for the high priority given to biomedical and clinical research, for example its ability to generate jobs, economic growth and national prestige, as well as strong and well-developed lobbying. A notable exception was the Philippines, which has a specific place for HPSR in its National Unified Health Research Agenda. ${ }^{7}$ Biomedical and clinical research are also better understood because they have existed as disciplines for longer than HPSR. These two research areas are also easily measurable in terms of publications, patents, job creation and income generation. HPSR outcomes are not yet easily measurable, which makes it difficult for funders to understand its impact and for decision makers to allocate funding for it.

\section{Interagency collaboration for health research needs strengthening}

In all eight countries/territories studied, interagency collaboration for health research and HPSR is visible, but needs strengthening. Participants from South Korea, the Philippines and Singapore described collaborations between the health, academic, science and technology, and health insurance organisations. However, different countries had different agencies that were either firstamong-equals or clearly dominant. This depended on historical, political and economic factors, which change over time. Several participants stated that because of this it was important to identify the correct agency to partner with, in order to maximise funding amounts.

Participants suggested several reasons to strengthen inter-agency collaboration, such as "health is multifactorial and not just scientific" (academic, Singapore), there is "a need for the funders, users and producers of HPSR to collaborate" (academic, Australia), and "interagency partnership increases the chances that the research output will be used" (HPSR institute, Malaysia). However, participants did not provide specific examples of how to strengthen inter-agency collaboration.

\section{Determinants of HPSR and health research funding decisions}

Funding criteria for HPSR funding are approximately similar to criteria for health research funding as a whole

Participants indicated a variety of determinants for HPSR funding. Examples included the quality and merit of HPSR proposals, their relevance to national health or development strategies, and potential for: increased effectiveness, efficiency or equity of healthcare services; 
cost savings or commercial value; societal or educational value; presence of interdisciplinary collaboration; and capacity-building. The participants stated that the funding criteria for HPSR were much the same as those for biomedical, clinical or public health research, without specific or additional criteria for HPSR. Participants also indicated that different HPSR funders, producers and users used different combinations and 'rank-orders' of importance for each of the above criteria; these combinations and prioritisations changed over time. This led to changes to the funding mix for biomedical, clinical, public health and HPSR research.

Responses to a follow-up question indicated that triggers or reasons for evolving priorities for HPSR included changes in leadership (whether political or technocratic), shifting disease burdens or healthcare needs of a country, shifting national or health strategies, and/or the availability of new evidence.

Participants from Australia and Singapore indicated that decision makers were increasingly using 'problembased frameworks' for funding decisions, for example, 'How can we reduce stroke morbidity and mortality rates?'. This approach differs from previous 'sectoral frameworks' for funding decisions, which allocated according to research categories. Malaysia has had a Health Research Priority program to support informed funding decisions since the late 2000s, but it is focused on biomedical or clinical research, rather than HPSR. ${ }^{8}$

\section{Involvement of political leaders increases overall research funding}

Some countries have political input into their research priorities; for example the Prime Minister of Singapore and the Federal Health Minister of Australia are involved in shaping research priorities (and therefore funding priorities). Other countries rely on senior technocrats for research priority-setting, for example, Malaysia and Hong Kong. For all countries, participants reported that decision makers (whether political or technocratic) were advised by senior scientists and researchers via governing councils, steering committees or advisory boards.

Participants suggested that large amounts of funding tend to be present when political leaders are involved. For example, Singapore's National Research Foundation is led by the Prime Minister and has committed to spending almost SGD25 billion (US\$19 billion) on overall research for 2021-2025. ${ }^{9}$ Australia's Medical Research Future Fund has US\$15 billion in capital, is led by the Health Minister ${ }^{10}$ and is separate from the National Health and Medical Research Council. ${ }^{11}$

\section{HPSR needs a bridging mechanism between funders, producers and users of research}

Participants suggested that HPSR functions in their countries appeared to be broadly divided into 'internal' health agency policy research units and 'external' universities, think-tanks and specialised institutes, with funders sitting separately. Several participants indicated that there was no bridge between the funders, producers and users of HPSR to allow output from nonhealth-agency organisations to be used by health agencies. Some participants believed that the presence of institutional or individual rivalries and bureaucratic inertia complicated matters.

Therefore, several participants believed HPSR needed to create a bridge between inhouse policy units in service delivery organisations and external researchers, to maximise output and outcomes through formalised engagement channels, for example with "joint secretariats" or "centrally-decided division of labour". This bridge would improve the balance between HPSR demand and supply. An example is Japan, which has made efforts to connect basic to applied researchers and universities to industry, establishing the Japan Agency for Medical Research and Development in 2008, with some involvement in HPSR. ${ }^{12}$

\section{Proposals to strengthen HPSR funding and contributions}

A synthesis of the in-depth interviews provided several suggestions to increase HPSR funding at national levels. All participants agreed that funding was only one part of the overall effort to increase the quality, quantity and relevance of HPSR output. Other elements included generating demand for HPSR output, building capacity for more and higher quality HPSR, and building pathways to translate HPSR output into real-world policies.

Appropriately use central agencies to raise HPSR as a national priority

In-depth interviews indicated that all researched countries had some form of central planning agency, although the relative strengths and influence of these agencies differed from country to country.

There are three types of central agencies for HPSR leaders to consider engaging with, like central planning agencies, treasuries or ministries of finance, or cabinetlevel research, science or health councils. Firstly, in some countries like China and Malaysia, there are 5-year national development plans, which can feature health research, especially in a post-pandemic world. These plans are led by non-finance ministry entities. For example, China's 14th Five Year Plan (2021-2025) is led by the Chinese Communist Party's Central Committee ${ }^{13}$ and has guided China's health system reforms. ${ }^{14,15}$ and the Twelfth Malaysia Plan (2021-2025) is led by its Economic Planning Unit ${ }^{16}$, which has significant influence in the political economy of health. Secondly, in all researched countries, the finance ministry is a powerful decision maker for research funding allocation, especially for biomedical and clinical research, which often forms part of the overall national research agenda; Thirdly, in some countries, 'apex' scientific or health-specific research councils decide priorities for overall scientific or health-specific research agendas. For example, in 
Singapore, the Research, Innovation and Enterprise Council is chaired by the Prime Minister ${ }^{17}$ and the Philippine Council for Health Research and Development is one of three sectoral councils in the Department of Science and Technology. ${ }^{18}$ In China and Japan, the National Health Commission ${ }^{19}$ and Headquarters for Healthcare Policies ${ }^{20}$, respectively, are responsible for health at the highest levels of government.

Several participants suggested making direct cases for HPSR to one of these three types of central agencies. HPSR could be advocated for as a priority in national development agendas, in funding priorities for finance ministries and/or in overall scientific or healthspecific research agendas. However, the participants recommended approaching these central agencies through 'appropriate bureaucratic channels'.

\section{HPSR should be more interdisciplinary}

Many participants believed that biomedical, clinical and public health researchers were increasingly keen to collaborate with HPSR experts because of evolving political and economic incentives for collaboration, as well as increased understanding of the value of HPSR. For example, there have been two consolidations in Hong Kong of research funders, ultimately creating a single Health and Medical Research Fund to encourage interdisciplinary research. ${ }^{21}$

Several participants suggested that HPSR leaders could embrace interdisciplinary research in two specific ways: 1) Leaders could advocate for HPSR components to be mandatory for selected competitive research grants at the national level. This could vertically integrate HPSR output into existing health systems and policy frameworks and better support national priorities. Outside of competitive research grants, HPSR leaders could also explore ring-fenced allocations for HPSR within the allocated budgets for biomedical and clinical research. Both steps would institutionalise the importance of HPSR in biomedical and clinical research. 2) HPSR leaders could invite biomedical, clinical, public health and social science researchers to partner for 'pure HPSR' projects. This would build familiarity, networks, trust and joint capability, while increasing the chances of grants and funding for HPSR.

\section{HPSR capacity and organisational structure is as important as HPSR funding}

Most participants indicated that HPSR funding alone was not enough to improve the quality, quantity and relevance of HPSR output. Alongside advocacy for additional funding, HPSR leaders must simultaneously build HPSR research capacity and integrate it into the overall healthcare delivery structure.

No participant reported an actual event where HPSR funding outpaced HPSR capacity development, that led to any failure to meet funders' expectations. However, several participants spontaneously commented on the importance of a calibrated approach between fundraising and capacity development for HPSR, to preserve the HPSR community's credibility for strong results.

\section{Discussion}

Although this research had limitations (see below), there appeared to be several similarities across the eight studied countries/territories in terms of funding of HPSR : 1) HPSR funding is perceived to be low, with funding predominantly going to biomedical/clinical or public health research; 2) participants believe that HPSR funding is as important as human resources and research infrastructure for delivering impactful HPSR output; 3) a wide interpretation of HPSR leads to a fragmented landscape of HPSR producers and users, which may lead to uncoordinated priorities between individual, institutional and national research agendas.

A synthesis of in-depth interviews indicates two additional fundamental similarities between countries. Firstly, participants believed that HPSR was struggling in comparison to the historically entrenched biomedical and clinical research sectors, which traditionally are perceived to be more prestigious, sometimes considered income generators, and which have measurable metrics like publications, citations, patents and commercial sales. Secondly, participants indicated that there is a 'chickenor-egg' situation when seeking to increase HPSR funding because funders may ask for an a priori demonstration of research capacity (which depends in large part on funding in the first instance).

This paper could be strengthened by additional research and data about the comparative aspects of HPSR funding, prioritisation and output between countries, stratified by income levels, population, total $R \& D$ spending, domestic/foreign breakdown of $R \& D$ funding sources, total number of health researchers, total number of HPSR researchers and the degree of public sector expenditure on healthcare. Future research can study the increasingly blurry lines between consultancy engagements and 'formal' HPSR projects, and collect appropriate funding statistics in both categories.

Other future areas of additional research or focus groups could be on ways to integrate HPSR into biomedical, clinical or public health research, new models to measure the impact of HPSR that achieve a balance between scientific, economic and social outcomes, and new incentive structures for HPSR that are both financial and non-financial.

\section{Limitations}

This research has several limitations. It was conducted for only eight WPRO countries/territories out of 37, it was also conducted in a relatively short timeframe during a highstress pandemic period, and the large structural gaps in funding data precluded a robust analysis of funding amounts for HPSR or its determinants. 
The limited amount of published data precluded a comparative analysis of HPSR funding between the eight WPRO countries/territories. Analyses of absolute and relative amounts, sources of funds (whether local/ international, public/private/philanthropy, or competitive grants), and whether HPSR was demand-led or supplyled require more hard data than are published. In-depth interviews indicate a wide range of heterogeneity between countries for these variables. Therefore, future research should consider that literature reviews and in-depth interviews may not be sufficient, and the national research strategies should include advocating for meaningful primary data collection at the national level by national governments.

\section{Conclusion}

This paper shows that countries in the Western Pacific region are familiar with HPSR and have varying levels of political, funding and institutional commitments to HPSR. Although data is generally absent for the amount of HPSR funding, R\&D funding is generally correlated with national GDP levels. The lack of a universal understanding of HPSR makes it difficult to compare HPSR funding between countries, although participants in the in-depth interviews believe that HPSR is underfunded compared to biomedical, clinical or public health research.

There are many types of decision makers for HPSR funding, although they use decision-making criteria that are similar to funding for biomedical, clinical or public health research. An important observation is that research funding increases whenever high-level political leaders are involved, such as prime ministers or ministers. There is an important role for central agencies (like treasuries, economic planning units or ministries of finance) in research funding, including HPSR funding. Participants in this study also believe that inter-disciplinary and interagency collaboration are important, and that additional HPSR funding must be accompanied by capacity building and institution building.

The coronavirus disease 2019 (COVID-19) pandemic has increased public and political attention on health systems and public health, and the pandemic's social effects have focused attention on health policies. The HPSR community in the WPRO can leverage this increased attention to strengthen the HPSR sector in the post-pandemic recovery phase, including appropriate increases in HPSR funding. The effects of COVID-19 on the HPSR infrastructure, funding, place on the political agenda and effective channels to translate HPSR to policy are still taking place, and the HPSR community has a once-in-a-generation opportunity to increase HPSR funding and strengthen its capacity and institutions.

\section{Acknowledgements}

This work was supported by the Alliance for Health Policy and Systems Research, World Health Organization. The authors are themselves alone responsible for the views expressed in the article. This article does not represent the views, decisions, or policies of the Alliance for Health Policy and Systems Research.

The author is grateful to Pascale Allotey (United Nations University - International Institute for Global Health) for editorial comments.

\section{Peer review and provenance}

Externally peer reviewed, invited. SKK is a guest editor of this themed issue of Public Health Research \& Practice. He had no part in the peer-review process for this paper.

\section{Competing interests}

None declared.

\section{Author contributions}

SKK conducted the research and interviews and was the sole author of the manuscript.

\section{References}

1. Alliance for Health Policy and Systems Research. What is health policy and systems research (HPSR)? Geneva: AHPSR; 2021 [cited 2021 Aug 25]. Available from: ahpsr. who.int/what-we-do/what-is-health-policy-and-systemsresearch-(hpsr)

2. Gonzalez-Block MA, Mills A. Assessing capacity for health policy and systems research in low-and-middleincome countries. Health Res Policy Syst. 2013;1(1):1.

3. The World Bank. Research and development expenditure (\% of GDP). Washington, DC: The World Bank; 2021 [cited 2021 Aug 25]. Available from: data.worldbank.org/ indicator/GB.XPD.RSDV.GD.ZS

4. UNESCO Institute for Statistics. Sustainable development goals: Science, technology and innovation. Paris: UNESCO; 2021 [cited 2021 Aug 25]. Available from: data.uis.unesco.org/Index.aspx?DataSetCode=SCN_DS\#

5. Cabinet Secretariat Office of Healthcare Policy. Annual Budgets. Japan: Prime Minister's Office; 2021 [cited 2021 Aug 25]. Available from: www.kantei.go.jp/jp/singi/ kenkouiryou/en/index.html

6. Marjanovic S, Chonaill SN. Health and medical research in Singapore. Observatory on health research systems. Cambridge: Rand Corporation; 2010 [cited 2021 Aug 25]. Available from: www.rand.org/content/dam/rand/pubs/ documented_briefings/2010/RAND_DB591.pdf 
7. Philippine National Health Research System. National unified health research agenda 2017-2022. Manila: Philippine National Health Research System; 2017 [cited 2021 Aug 25]. Available from: doh.gov.ph/sites/default/ files/publications/NUHRA.pdf

8. Fun, WH, Sararaks S, Tan EH, Tang KF, Chong DWQ, Low LL, et al. Research funding impact and priority setting - advancing universal access and quality healthcare research in Malaysia. BMC Health Serv Res. 2019;19(1):248.

9. National Research Foundation. Singapore: Prime Minister's Office; 2021 [cited 2021 Aug 25]. Available from: www.nrf.gov.sg

10. Medical Research Future Fund. Department of Health. Canberra: Australian Government; 2021 [cited 2021 Aug 25]. Available from: www.health.gov.au/ initiatives-and-programs/medical-research-future-fund

11. National Health and Medical Research Council. Research funding statistics and data. Canberra: NHMRC, Australian Government; 2021 [cited 2021 Aug 25]. Available from: www.nhmrc.gov.au/funding/data-research/researchfunding-statistics-and-data

12. Burgdorf JR. Health and medical research in Japan. Observatory on health research systems. Cambridge: Rand Corporation; 2010 [cited 2021 Aug 25]. Available from: www.rand.org/content/dam/rand/pubs/documented_ briefings/2008/RAND_DB571.pdf

13. Proposal of the Central Committee of the Communist Party of China on formulating the 14th five-year plan for national economic and social development and the vision goals of 305. Beijing: Xinhua News Agency; 2021 [cited 2021 Aug 25]. Translated version available from: cset.georgetown. edu/publication/proposal-of-the-central-committee-of-thechinese-communist-party-on-drawing-up-the-14th-fiveyear-plan-for-national-economic-and-social-developmentand-long-range-objectives-for-2030/
14. Meng Q, Mills A, Wang L, Han Q. What can we learn from China's health system reform? BMJ. 2019;365:12349.

15. Meng Q, Shi G, Yang H, Gonzalez-Block M, Blas E. Health policy and systems research in China. Special programme for research and training in tropical diseases. Geneva: World Health Organization; 2004 [cited 2021 Oct 27]. Available from: www.who.int/tdr/publications/documents/ health-research-china.pdf?ua $=1$

16. The Malaysian Administrative Modernisation and Management Planning Unit. Twelth Malaysia plan. Putrajaya, Malaysia: Economic Planning Unit, Prime Minister's Department [cited 2021 Aug 25]. Available from: www.malaysia.gov.my/portal/content/31186

17. Research, Innovation and Enterprise Council. Singapore: Prime Minister's Office, National Research Foundation; 2021 [cited 2021 Aug 25]. Available from: www.nrf.gov.sg/ about-nrf/governance/research-innovation-and-enterprisecouncil-(riec)

18. Philippine Council for Health Research and Development. Manila: PCHRD; 2021 [cited 2021 Aug 25]. Available from: www.pchrd.dost.gov.ph

19. Wang L, Wang Z, Ma Q, Fang g, Yang J. The development and reform of public health in China from 1949 to 2019. Global Health. 2019;15:45.

20. Sakamoto H, Rahman M, Nomura S, Okamoto E, Koike S, Yasunaga $\mathrm{H}$, et al. Japan health system review. Geneva: World Health Organization; 2018 [cited 2021 Oct 27]. Available from: apps.who.int/iris/ bitstream/handle/10665/259941/9789290226260-eng. pdf? sequence $=1$ \&isAllowed $=y$

21. Research Fund Secretariat, Food and Health Bureau. Health and Medical Research Fund. Hong Kong: The Government of the Hong Kong Special Administrative Region; 2021 [cited 2021 Aug 25]. Available from: rfs1. fhb.gov.hk/english/funds/funds_hmrf/funds_hmrfabt/ funds_hmrf_abt.html

\section{Copyright: (c) (1)}

(c) 2021 Khor. This article is licensed under the Creative Commons Attribution-NonCommercial-ShareAlike 4.0 International Licence, which allows others to redistribute, adapt and share this work non-commercially provided they attribute the work and any adapted version of it is distributed under the same Creative Commons licence terms. See: www.creativecommons.org/licenses/by-nc-sa/4.0/ 